\title{
"Urban Agriculture Commercialization; an Alternative to Food Security" (Case of Mekelle City)
}

\author{
Gebrekiros Hagos $^{1 *}$, Abrha Gebreslassie ${ }^{2}$, Amanuel Teklay ${ }^{1}$, Mulugeta Tesfay ${ }^{2}$ \\ ${ }^{1}$ Department of Management, Mekelle University, Ethiopia \\ ${ }^{2}$ Department of Economics, Mekelle University, Ethiopia \\ *corresponding author: naodgk@gmail.com
}

\begin{abstract}
The study was commenced with the general objective of urban Agriculture commercialization specifically Dairy Product in Mekelle city, Tigrai Ethiopia .100 households were selected using simple random sampling method. Data were collected using formal survey which is questionnaire. The data collected were processed using both descriptive and two stage least square method/ Multiple regression econometric models specifically logit model. The binary Dairy Product model results revealed that Extent of education of the household head, family size, distance to the nearest market center, and total Dairy Product owned played significant role in commercialization decision. The second-step selection estimation indicated that Extent of education of the household head, visit by extension agents, total dairy products owned and owned land size significantly affected Extent of commercialization measures the fraction of sales to the total value of dairy products owned by the household. The researchers recommend that any stakeholder, institutions like agricultural institute, government with its extension workers and other development institutions and partners should give due emphasis on capacity building through formal and informal ways, which increases the owner of the Dairy Product a bargaining power in the market by getting information related price, demand and supply, production and management technologies Besides, facilitate Dairy Product market outlets near to them in the region and creating an interface with other regions, which minimize operation and increment efficiency. Finally, stakeholders should give emphasis to the major challenges of market infrastructure, shortage in pasture lands and disease for they could create a bottleneck effect in the remedy and food of the society positively and negatively measuring their implementation performance.
\end{abstract}

Keywords: Dairy Products, Urban Agriculture, commercialization, binary Dairy Product model, Extent of commercialization.

http://dx.doi.org/10.21776/ub.agrise.2020.020.3.5

Received 19 May 2020

Accepted 30 June 2020

Available online 29 July 2020

\section{INTRODUCTION}

Poverty and food insecurity are the greatest challenges for Ethiopia. Poverty is manifested in many forms including low income ${ }^{1}$, poor access to basic health services and safe drinking water ${ }^{2}$, high infant mortality rate and low life expectancy. However, poverty in Ethiopia is mainly expressed in terms of its worst form: food poverty and starvation (Zenebe, 2008). In Ethiopian, specifically Tigray regional state, Agriculture has been a subject to considerable state interest and intervention over the past 25 years, possibly more than any economic sector. This trend may not be overwhelming since agriculture continues to be a strategic sector in the development of most low-income nations. It employs about $40 \%$ of the active labor force globally (Robinson, 1989; Gardner, 1990). In sub-
Saharan Africa, Asia and the Pacific, the agriculturedependent population is over $60 \%$, while in Latin America and high-income economies the proportions are estimated at $18 \%$ and $4 \%$, respectively (World Bank, 2010). Close to two thirds of the natural wealth in low-income countries is embodied in crop and pasture land. The agricultural sector employs $70 \%$ of the national labor force through forward and backward industrial linkages, thus provides food and incomes to individuals and households (FAO, 2007).

The concrete interest of government in the agriculture sector paves the need for urban agriculture. Urban farming is the growing of plants and raising of animals for food and other uses within cities and peri-urban areas as well as, related activities like the production, delivery of inputs,

\footnotetext{
${ }^{1}$ (estimated at $\$ 100$ per capita)

2 (only about $24 \%$ have access to safe water) 
processing and marketing of products (Urban Agricultural Magazine, 2001). The benefit of urban farming is hinged on availability of productive land and water resources for this economic group. Despite commercialization of many industrial and consumer goods in urban areas, in agricultural commercialization, government can do a great deal to enhance market participation of low income urban consumers by supporting the development of efficient private sector food marketing system in the urban. Commercialization is the movement from a subsistence production to a market-based system of production. It involves raising the cash earnings of small-scale, agricultural related enterprises. Increasing the unit of output, raising the value added or both, producing for domestic and foreign markets leads to commercialization. It can be conceptualized from both input and output side. According to Von Braun et al, 1994, the degree of participation in the output market is the conventional way to measure commercialization.

However, commercialization is contingent upon the availability of input and output markets, agroclimatic conditions and risks; infrastructure, community and household resource and asset endowments; the development of local commodity, input, laws and institutions (Pender et al., 2006). It is a complex and dynamic process involving several dimensions related to technology, markets, finance, institutions, infrastructure and social structure. Nonetheless, past efforts to improve smallholder farmers' access to markets through market reforms have largely been ineffective. Consequently, majority of smallholder farmers still produce largely for subsistence needs, producing small marketable surpluses and faces thin markets. Such markets are characterized by low activity, low volumes and noncompetitiveness (Obare et al, 2006). The farmers face difficulties in transporting their produce to the markets which often force them to sell at the farm gate. Similarly, lack of coordination among smallholder farmers limit their ability to bargain for higher prices, have access to information and credit, hence, dampen the incentives to commercialize and expand production (World Bank, 2002 cited in Roseline et al, 2013)

\section{Problem statement}

The variety nature of urban agriculture (UA) is one of its main attributes, as it can be adapted to a wide range of urban situations and to the needs of diverse stakeholders (FAO, 2007). Furthermore, rapid population growth and urbanization creates high demand for food and require urgent supply response to prevent widespread lack of food and in that way to create alternative food security aspect especially among low income consumers (Pingali et al, 2006) to this end improving efficiency can play a very significant role in enhancing urban consumers food security (Roseline et al, 2013).

Though scientific debate encompassing urban agriculture focuses on competition for nonrenewable resources ${ }^{3}$ and its economic viability, urban agriculture is taking the helm where Rural Agriculture (RA), the prime producer of food in urban, failed to achieve urban food security. It complements RA in terms of self-provisioning, marketing flows and market supply flows. Unprecedentedly, there is a growing concern that RA will deprive lands (through land grabbing) from rural populations and trigger its movement toward cities thereby reducing rural populations. However, UA is highly unlikely to turn urban households fully self-sufficient in all of the food which they may require. The major obstacles in urban agriculture are determining how to monitor and control economic and social environment; and understanding how UA can be a sustainable component of the global urban food systems. Those who opposed the essentiality of urban agriculture emphasizes on the negative impacts of UA, related to health risks, productivity and pollution, proponents counter these sentiments by emphasizing the viability of UA in terms of increasing the locality of food and reduction of energy expenditure in production (Ibrahim and Richaela, 2015).

In Ethiopia, the existence of large Dairy Product capacity along with some contributing factors like favorable climate for improved dairying, and the relatively disease-free highland environment with potential for animal feeding (Anteneh et al. 2010) and a huge gap between demand and supply of milk (Tegegne et al. 2007) have created a large advantage for the commercialization of diary. Though there is market-oriented Dairy Product development, urban agricultures' dairy development performance and its contribution to poverty reduction and economic development has remained very low. In Tigray regional state, urban dairy system is characterized by a production system in which cattle are permanently kept indoors. Urban dairy farmers have little or no agricultural land and most inputs are bought from market. The sale of fluid milk is the major source of income from dairying. Urban dairy farmers tend to be better educated, better off financially and are more receptive to education and technologies (Nigatu et al, 2012).

In urban agriculture, indicators are key parameters showing and measuring change and impact. Moustier (2001) sees the following economic indicators as important in assessing economic impact of urban agriculture at the household Extent: employment (population involved), income and income distribution, cash

3 (i.e., soil, water, land) 
readiness, contribution to household food, addedvalue, relative contribution to urban food supply, and share in market(s). Clearly, the studies reviewed do not provide information on these indicators. In order to understand impact and household strategies to that of food security with respect to urban agriculture, other factors that influence subsistence and/or income are important and must be analyzed. The valuation of socio-economic impact will differ greatly according to the types of indicators used, and its omission may lead to differing estimates. Focusing on subsistence agriculture may underestimate the economic impact of commercial agriculture, and conversely, those focusing on commercial agriculture may underestimate the food security and livelihood roles of urban agriculture.

\section{Objective}

This article aimed to investigate urban agriculture commercialization in enhancing food security of dwellers. Specifically, we tried to:

a. Explain existing problems facing urban agriculture from study area.

b. Investigate the determinants of diary productivity involved in urban agriculture

c. Examine the extent of commercialization from micro-perspective

\section{RESEARCH METHODS}

\section{Description of the study area}

Mekelle, the capital city of the Tigrai National Regional State, lies $780 \mathrm{~km}$ north of Addis Ababa. It can be reached by plane and bus. Spread out on a plain and partly encircled by a chain of mountains, Mekelle covers $28 \mathrm{~km}$ square and has an estimated population of 323,700 according to the census results and latest official projections. Mekelle has more recently become a town where rapid political and economic developments are taking place. It is also becoming an educational center, with amazing proliferation of institutions of public and private higher learning. Mekelle city have 7 weredas (districts) namely Quha, Hdnet, Adi Haqi, Kedamay Weyane, Semen, Hawelti and Ayder.

\section{Research strategy and design}

Research design is the strategy, plan and structure of conducting a research project (Leedy, 1993). The choice of an appropriate research method depends on the purpose and topic of a study (Babbie \& Mouton 2001). The research study was include qualitative and quantitative, descriptive and cross sectional research design. This study was incorporate both quantitative and qualitative research approaches in order to generate the advantage of both approaches like; to address different objectives of the study, which cannot be achieved by a single method; and to enable one approach to inform another approach, either in design or in interpretation. As well as to triangulate the findings of different approaches (either performed concurrently or sequentially) in an effort to provide greater confidence to the study. McKerchar (2010) argues that "each strategy has its strength and weaknesses and the drive for mixed method research is to use one strategy to either inform, validate or compensate for the weaknesses of another".

\section{Type of Data and Source of Data}

Quantitative Data: According to Leedy and Ormrod (2005), a study is classified as quantitative, if the researcher wants to quantify the variation in a phenomenon, situation, problem or issue, if information is gathered using predominantly quantitative variables, and if the analysis is geared to ascertain the magnitude of the variation. Additionally, quantitative research is used to develop and employ mathematical models, theories, and hypotheses pertaining to natural phenomena. Therefore, quantitative data in this study will be collected to search out desirable answer particularly issues that are directly related to the determinants of productivity in diary production.

Qualitative Data: A study is categorized as qualitative, if its intention is primarily to describe a situation, phenomenon, problem, or event. i.e., the information is gathered using variables measured on nominal or ordinal scales (that is, qualitative measurement scales); and an analysis is done to establish the variation in the situation, phenomenon or problem without quantifying it (Leedy and Ormrod, 2005). Thus, qualitative data is used for this study which focuses to get desirable answers for existing problems facing urban agriculture from micro-perspective.

Primary sources: The sources of primary data for this study were obtained from those individuals or enterprises who are involved in dairy production and those who are in the chain of dairy products for commercialization. Moreover, regional concerned government officials will be considered for in-depth interview.

Secondary Sources: - Published and unpublished works, documents from different concerned offices, and other social Medias were used as a source for secondary data. Though information for this study will be generated from primary and secondary sources, the importance of secondary data will not be overemphasized.

\section{Data Collection}

The instruments that will be applied to use for this study is questionnaires (both close ended and openended questionnaires), observation and in -depth interviews were conducted so as to obtain relevant information to make the research findings more 
valuable. As result the primary data were collected with questionnaires, and interview. The questionnaires were distributed to sample respondents. Most of the structured questions were close-ended type and respondents were asked to mark the appropriate box matching the correct answer. Other questions, however, were requiring respondents to give opinions. Moreover, an in-depth interview questions were also be prepared and administered again to the concerned government representatives.

\section{Target Population and Sampling}

As indicated above the target population is those individuals or enterprises who are involved in dairy production and those who are in the chain of dairy product for commercialization. As a result Individuals or enterprises who are involved in dairy production found in Mekelle city will purposely be selected. From previous lessons and different studies conducted in the area, we come to know that a target population of 150 individuals or enterprises who are involved in dairy production is recommendable to conduct the study. However in order to investigate the commercialization and food security aspect of the study, sampling determination procedure by Glenn D. Israel(1992) has adopted (please find attached the table of sampling), as a result for a population of $>100,000$ it is recommended that 100 respondent as a sample with $10 \%$ precision.

Table 1. Sample size for $+3 \%,+5 \%, \pm 7 \%$ and $+10 \%$ Precision Level Where Confidence Level is $95 \%$ and $\mathrm{P}=5$

\begin{tabular}{ccccc}
\hline \multirow{2}{*}{ Size Population } & \multicolumn{4}{c}{ Sample Size $(\mathrm{n})$ for Precision (e) of: } \\
\cline { 2 - 5 } 500 & $\pm 3 \%$ & $\pm 5 \%$ & $\pm 7 \%$ & \pm 3 \\
600 & $\mathrm{a}$ & 222 & 145 & 86 \\
700 & $\mathrm{a}$ & 240 & 152 & 88 \\
800 & $\mathrm{a}$ & 255 & 158 & 90 \\
900 & $\mathrm{a}$ & 267 & 163 & 91 \\
1,000 & $\mathrm{a}$ & 277 & 166 & 95 \\
2,000 & $\mathrm{a}$ & 286 & 169 & 97 \\
3,000 & 714 & 333 & 185 & 98 \\
4,000 & 811 & 353 & 191 & 98 \\
5,000 & 870 & 364 & 194 & 98 \\
6,000 & 909 & 370 & 196 & 99 \\
7,000 & 938 & 375 & 197 & 99 \\
8,000 & 959 & 378 & 198 & 99 \\
9,000 & 976 & 381 & 200 & 99 \\
10,000 & 989 & 383 & 201 & 99 \\
15,000 & 1,000 & 385 & 204 & 100 \\
20,000 & 1,034 & 390 & 204 & 100 \\
25,000 & 1,053 & 392 & 204 & 100 \\
50,000 & 1,064 & 394 & 204 & 100 \\
100,000 & 1,087 & 397 & 204 & 100 \\
$>100,000$ & 1,099 & 398 & 204 & 204 \\
\hline
\end{tabular}

$\mathrm{a}=$ assumption of normal population is poor (Yamane, 1967). The entire population should be sampled

\section{Data analysis}

Both simple descriptive statistics and econometric model were employed so as to analyze the data found from various sources. In using simple descriptive statistics, we were applying averages, percentages, tables, charts, and the like. However, in applying econometric model, we had employed different models which go in line with the specific objects. Details of the specific models are described as follows:

\section{Model Specifications}

In section 3 above, we have identified four specific objectives so as to address the issue of our study. In doing so, we will analyze the first objective using simple descriptive statistics and qualitative data analytical method. However specific objective number two is going to be analyzed by employing the empirical multiple regression model (Wooldridge, 2010) - and similar model namely The single-Equation Linear Model suggested by Verbeek (2004) - described as follows:

$Y_{i}=\beta_{i} X_{i}+\varepsilon_{i}$

Where $Y_{i}$ (Dependent Variable) represents the dairy productivity; $\mathrm{x}_{\mathrm{i}}$ is vector of explanatory variables; $\beta_{\mathrm{i}}$ stands for vector of parameters which are nonrandom but unknown quantities; and $\varepsilon_{\mathrm{i}}$ is noise terms which are random and unobserved. The dairy productivity were measured milk (in liters) per cow per day; and the vector of explanatory variables 
were include number of cows owned, type of cows, educational status of any of household members, gender of the household head, household size, age composition of the household, access to animal fodder, access to and size of land ownership, access to market, Extent of competition, Other income of the household earned from activities other than dairy production, time spent on rearing the cows, and others.

On the other hand, the third specific objective needs to be assessed by the Multinomial logit model (Verbeek, 2004; and Wooldridge, 2010). In this objective our interest is to see the extent of sales of dairy products. Stating differently, part of the product may be used for sales, some of it for own consumption, and the rest (if any) defected. Therefore, we were first developing cut-off points and then determine what factors were affect the extent of their sales. To this end, as mentioned above, the factors these affect extent sales were analyzed using Multinomial logit model because the logit model for binary outcomes extends to the case where the unordered response has more than two outcomes. The probability that a respondent lays within alternative $j$ can be (assumed to be) described by a multinomial logit model, with

$$
P\left\{y_{i}=j\right\}=\frac{\exp \left\{x_{i j}^{\prime} \beta\right\}}{1+\exp \left\{x_{i 2}^{\prime} \beta\right\}+\cdots+\exp \left\{x_{i j}^{\prime} \beta\right\}}
$$

The last specific objective is going to be analyzed using dynamic panel models using a recall data. The need here is to look at what happens to the Extent of food security to the urban dwellers when there is change in dairy production. According to Stephen R. Bond (2002), when the number of individuals for which data is available $(\mathrm{N})$ is assumed to be large whilst the number of time periods for which data is available (T) is assumed to be small, and asymptotic properties are considered as $\mathrm{N}$ becomes large with $\mathrm{N}$ fixed, we can focus on estimation methods for the simple Autoregressive (1) Model as follows:

$y_{i t}=\alpha y_{i, t-1}+\left(\eta_{i}+u_{i t}\right) ; \quad|\alpha|<1 ; \quad i=1,2, \ldots, N ; \quad t=2,3, \ldots, T$

Where $y_{i t}$ is an observation on some series for individuals $i$ in period $t, y_{i, t-1}$ is the observation on the same series for the same individual in the previous period, $\eta_{i}$ is an unobserved individualspecific time-invariant effect which allows for heterogeneity in the means of the $y_{i t}$ series across individuals, and $u_{i t}$ are independents across individuals.

\section{RESULT AND DISCUSSION}

\section{Socio-economic Constraints}

Among the socio-economic constraints, land is the major challenge faced by people engage in urban agriculture especially for the dairy production. The survey questionnaire on assessing the dairy production area problem encountering the urban farmers revealed that 68 household responded that they are facing problem of dairy production land, and 31 household says they don't have suffice land area to facilitate Urban Agriculture as long as they are practicing their dairy production system on the marginal and scrappy land area.

Although the Urban Agriculture practitioners in the study are have access to major market sites in their locality, the marketing facilities not well organized so that urban farmers are brought to problems such as loss of dairy products, price manipulation by middle-men, fluctuation of consumers interest for dairy products. The research made to reveal the problems of market on Urban
Agriculture products in the study area results, 70 respondents among the 100 sample HHs suggested that they are facing the problem of market due to the above-mentioned factors. The Table below shows the responses from respondent on the market related constraints of urban agriculture specifically the dairy product.

Tabel 1. Market related constraints of urban agriculture

\begin{tabular}{lccc}
\hline \multicolumn{1}{c}{ Variables } & Yes & No & Total \\
\hline Low price & 52 & 48 & 100 \\
\hline Low interest of consumers & 25 & 75 & 100 \\
\hline Poor market facilities & 53 & 47 & 100 \\
\hline $\begin{array}{l}\text { Price manipulation by middle } \\
\text { men }\end{array}$ & 36 & 64 & 100 \\
\hline
\end{tabular}

Source: Own survey, 2018

Tabel 2. Challenges of Urban Agriculture

\begin{tabular}{lccc}
\hline \multicolumn{1}{c}{ Variables } & Yes & No & Total \\
\hline $\begin{array}{l}\text { Threats of } \\
\text { urbanization, } \\
\text { investments, and } \\
\text { industrialization }\end{array}$ & 63 & 37 & 100 \\
\hline Eviction from parcel & 47 & 53 & 100 \\
\hline Shrinkage of parcel & 46 & 54 & 100 \\
\hline Pollution & 53 & 47 & 100 \\
\hline
\end{tabular}

Source: Own survey, 2018 
One of from the respondent members who engaged in dairy production confessed, he and his relatives during the rainy season they are engaged in collection of plastic sheets released from industries which is MOHA to cannel which is found in Mekelle city. This implies that pollution does not only affect the soil, cows and water resources even it competes with the time and energy of urban farmers.

The soaring price of Dairy Product feed is also the profound challenge for the dairy and poultry farmers in the study area. As the participants demonstrate the problem the rate for the increment of Dairy Product feed is double fold of the price of Urban Agriculture products so that the return from sell of the products couldn't be compensating the farm production cost.

\section{Opportunities of Urban Agriculture \\ a) The Emergence of Micro and Small Enterprises}

The survey 100 households also come about MSEs in Mekelle city have enormous benefits for the Urban Agriculture practitioners. Accordingly, data collected on the merits of MSEs with the following question, "Do you feel that being organized in a micro and small enterprise has an advantage for implementing the urban agriculture?", thus, 96 percent of the respondents said "yes". Besides, the advantages of MSEs are described listed below:

Table 3. The advantages of MSEs

\begin{tabular}{lllc}
\multicolumn{1}{c}{ Variables } & Yes & No & Total \\
\hline Advantageous to get access to credit service & 80 & 20 & 100 \\
Advantageous to get access to land or space for work & 87 & 13 & 100 \\
Advantageous to get access for technical support & 75 & 25 & 100 \\
Advantageous for contribution of labor and inputs among & 56 & 44 & 100 \\
members & & & \\
\hline
\end{tabular}

Source: Own survey, 2018

We have drawn findings from the data in Table above that the challenges mentioned in the first part such as land and the weak technical support delivered to urban farmers are tend to be
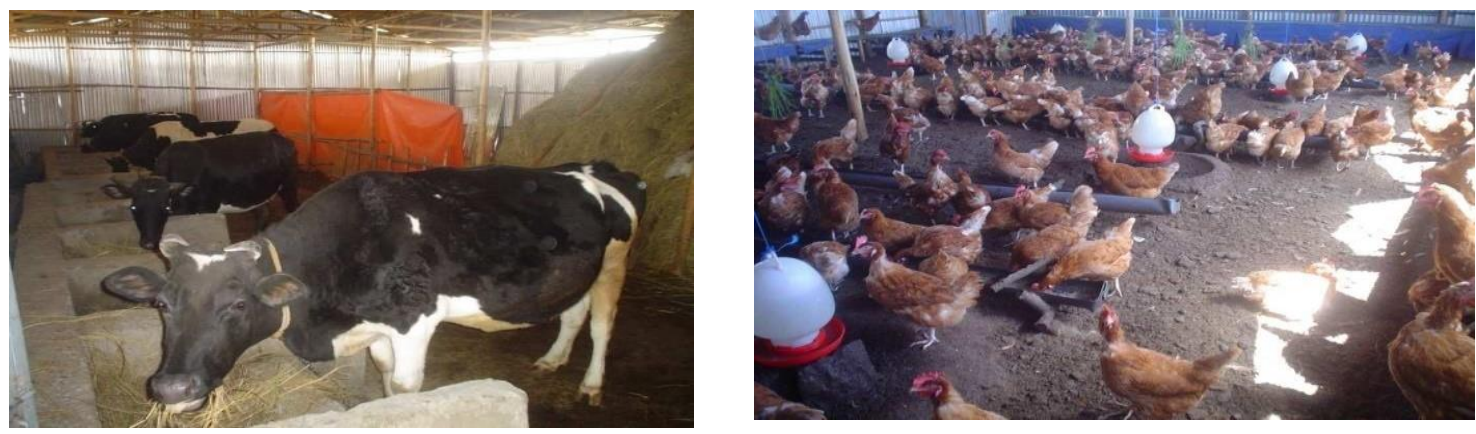

Source: Own survey, 2018

Socioeconomic characteristics of Dairy Product market participants and non-participants, out of the 100 households, $88 \%$ were commercializing their dairy products while the remaining $(12 \%)$ did not commercialize, they simply rear them for prestige and way expressing wealthy and way of life.

The table below shows that out of the total surveyed households' majority of them ( $88 \%$ ) were commercializing (participating) at the time of the study. For this reason, the researchers can conclude that household may have total commercializing for resolved by the opportunities created through MSE thus it would be better for them to engage in the organized efforts rather than individual basis. sake of profit making but not to get return from investment and this leads to get more participants in the market of dairy products.

Table 4. Commercialization

\begin{tabular}{lcc}
\hline \multicolumn{1}{c}{ Commercialization } & Frequency & Percent \\
\hline Not commercializing & 12 & 12 \\
Commercializing & 88 & 88 \\
Total & 100 & 100 \\
\hline
\end{tabular}

Source: Own survey, 2018 


\section{Factors Affecting Dairy Product} commercialization

Dairy products (urban agriculture) were produced for way of life, prestige, consumption and commercialization in the urban area (Mekelle city). Various variables are assumed to determine urban agriculture commercialization and the extent of commercialization by sampled dairy household.

The study used the variance inflation factor to check multi-co linearity among continuous Variables. According to the test results there was an average Vif (tolerance) of 1.87 . Which is below 10 and tolerable (multi-co linearity was not a serious problem). As a result, all the variables in the list were considered for the model analysis.

\section{Regression output of the Econometrics two stage analyses}

The Dairy Product estimation predicts the probability of commercializing decision in the dairy product market by each household; in the second regression, it analyses the determinants of Extent of dairy product commercialization.
Maddala (1983) suggested using selection variable that is assumed to affect the commercialization decision largely, but not Extent of commercialization in the selection equation, which enables the inverse Millis' ratio to predict correctly. Accordingly, this study used distance as selection variables in Dairy Product model/commercialization equation which was found to affect the Dairy Product market commercialization decision, but has no significant impact on Extent of commercialization in order to predict lambda (inverse Mill's ratio) correctly.

The binary Dairy Product equation/ dairy product commercialization decision Equation

The model output reports result of estimation of variables that are expected to determine Dairy Product commercialization by households. Education Extent of the Household head, family size, distance to the nearest market centre and total Dairy Product owned were found to determine the probability of Dairy Product commercialization decision.

Table 5. Dairy Product model estimation results of factors affecting probability of Dairy Product commercialization decision model

\begin{tabular}{lcr}
\hline \multicolumn{1}{c}{ Variable } & Coefficient & $\mathbf{p}>/ \mathbf{z} /$ \\
\hline hhage & -0.057 & 0.352 \\
HHeduc & 0.061 & $0.032^{* *}$ \\
hhsex & 2.152 & 0.532 \\
Family size & 0.536 & $0.001^{*}$ \\
distance & -0.851 & $0.036^{*}$ \\
Visit by extension agents & 0.752 & 0.253 \\
Total Dairy Product owned & 0.0526 & $0.000^{*}$ \\
Market information & 0.521 & 0.271 \\
Owned land size & 0.2856 & 0.145 \\
constant & 15.54213 & \\
\hline
\end{tabular}

Notes: Observations $=100$, Pseudo $\mathrm{R}^{2}=0.59 .67$..

** And *: statistically significant at $5 \%$ and $1 \%$ respectively

Family size: The variable is statistically significant at less than $1 \%$ significance Extent. As it is anticipated, the variable has a + ve effect on the probability of commercialization result. The positive and significant relationship indicates that as Dairy Product childhood is labor intensive activity, larger family size provides higher labour to undertake Dairy Product keeping in production and management activities easily which in turn increases volume leading to increased capacity of Dairy Product market commercialization decision.

Extent of education of the household head: as expected, Households with literate heads have higher Dairy Product commercialization. Literacy of head increases the proportion of output sold by about $9.6 \%$ on average for the population of study.
Total Dairy Product owned: total Dairy Product owned is positively related and statistically significant with the Dairy Product market commercialization decision. The marginal effect of the variable reveals that an increase in one Dairy Product in the household results in $9.8 \%$ increase in the Dairy Product market commercialization decision because many in number could result in high surplus of Dairy Product left from consumption and/or way of life which can increase the motivation of households to sell the extra in the Dairy Product market.

Distance and location: as forecasted distance to the bordering market center has -ve effect on commercialization of household and found to be statistically significant at less than $\mathbf{5 \%}$ significance Extent. This could be due to the reason that their 
decision will be diverted to simply consumptions or way of life than selling and buying new ones etc.

The negative relationship indicates that the farther is a household from the nearest Dairy Product market, the more difficult and costly it would be to get involved in the market.

\section{Estimation results of second stage econometrics selection model:}

The results of second stage Econometrics selection estimation for extent of household commercialization in Dairy Product market in terms of amount of sales of Dairy Product (cow, ox, sheep, and goat) are presented in Table below. The overall joint goodness of fit for second stage Econometrics selection model parameter estimates is assessed based on Wald chi-square test.

The model chi-square test applying appropriate degree of freedom indicates that the overall goodness of fit for second stage Econometrics selection model is statistically significant at a probability of less than $1 \%$. It shows that jointly independent variables included in Econometrics selection model explained Extent of commercialization in Dairy Product sales. In the Econometrics second stage selection model, four explanatory variables: Extent of education of the household head, visit by extension agents, Total Dairy Product owned, owned land size had significantly affected Extent of Dairy Product commercialization.

Tabel 6. Results of second stage Econometrics selection estimation for Extent of Dairy Product commercialization

\begin{tabular}{lrrr}
\hline \multicolumn{1}{c}{ Variable } & Coefficient & \multicolumn{1}{c}{ Standard Error } & \multicolumn{1}{c}{$\mathrm{p}>/ \mathrm{z} /$} \\
\hline Age of Household head & -0.00452 & 0.00896 & 0.214 \\
Extent of education of household head & 0.30670 & 1.37423 & $0.0672^{* *}$ \\
Sex of household head & -0.18756 & 0.15876 & 0.423 \\
Family size & 1.2831 & 0.5939 & 0.365 \\
Distance to nearest center & -1.08752 & 0.265590 & 0.412 \\
Transportation access to market center & 0.34761 & 0.34672 & 0.856 \\
Visit by extension agents & 0.8546 & 0.50636 & $0.076^{* * *}$ \\
Total Dairy Product owned & 0.5423 & 0.72562 & $0.002^{*}$ \\
Access to market information & 6.8945 & 5.37214 & 0.986 \\
Previous year's Price & 0.42765 & 0.34756 & 0.147 \\
Owned Land size & .6954 & 0.2006 & $0.006^{*}$ \\
Lamda & -0.4509 & 0.401 & 0.129 \\
\hline
\end{tabular}

Source: Own survey, 2018

Observations $=100$, censored observations $=88$, uncensored observations $=22$, wald $\mathrm{chi}^{2}(11)=84.35^{*}, \mathrm{Rho}=-$ 4.9562 , sigma $=2.2352 . * * *, * *$ And $*$ : statistically significant at $10 \%, 5 \%$ and $1 \%$ respectively.

Household Extent of education: Education Extent of the household head has positive effect on Extent of commercialization and it is statistically significant at less than $10 \%$ probability Extent. The positive and significant relationship indicates that education improves the Dairy Product household capacity to process production related and market related information, which in turn improves bargaining position. The model output confirms that one formal year education leads the Dairy Product household to increase Extent of commercialization in sales of Dairy Product by $30.6 \%$.

Total Dairy Product owned: total Dairy Product owning is positively related and statistically significant with the Extent of commercialization. This indicates that ceteris paribus, an increase in Dairy Product volume per household results in $54.23 \%$ increase in the Extent of commercialization. This is because stock of Dairy Product would result in high surplus left from way of life and consumption which can increase the involvement of farmers in Dairy Product market.

Visit by extension agents: The model result shows that extension services given by the respective office to the household head had a positive and significant effect on Extent of Dairy Product market commercialization of the sampled Dairy Product households. The positive and significant relationship between the two variables indicates that an additional service and training related to production, management and marketing given by the respective officers could increase the household head's capacity to produce and manage the Dairy Product and access necessary information on market, production and management of the Dairy Product thereby increasing the probability of the household Extent of Dairy Product market commercialization. The coefficient also confirms 
that when the household gets visited by extension agents (access to extension service increases by one unit), the probability of household head's Extent of Dairy Product commercialization increases by $85.46 \%$.

Owned land size in hectare: land size has positive effect on Extent of Dairy Product commercialization and found to be significant at $1 \%$ probability Extent. The positive relation between the variables shows that any additional hectare of land creates a capacity to produce food to the Dairy Product and space for rearing which can contribute to increase Dairy Product per household and then contribute to increase Extent of Dairy Product market commercialization. The coefficient also confirms that when the household owned land increases by one hectare, the probability of household head's Extent of Dairy Product commercialization also increases by $69.54 \%$.

Lamda: According to the model output, the Lambda (Inverse Mills Ratio) or selectivity bias correction factor has negative, but statistically insignificant impact on Dairy Product commercialization. This result suggests that there appears to be no unobserved factors that might affect both likelihood (probability) of Dairy Product commercialization decision and thereby affecting the Extent of commercialization.

\section{CONCLUSION}

The study was undertaken with the objective of urban Agriculture commercialization in Mekelle city, Ethiopia. Commercialization decision and the extent of commercialization in cash value of the dairy products sold are found to be important elements in the study of Diary product market. The two-stage econometrics analysis was used in order to internment the discrimination bias and get the impact on commercialization decision and extent of commercialization of Dairy product per household. Commercialization in Dairy product market is a dichotomous dependent variable, thus in the first stage of the two stage econometrics model procedures, and the maximum likelihood estimation procedure, binary Dairy Product model was used.

The maximum likelihood Dairy Product model analysis revealed that Extent of education of the household head, family size, distance from the nearest market center and total Dairy Product owned were found to bring significant effect on probability of the household's Dairy Product commercialization decision. However, the selection equation procedure identified education Extent of the household, total Dairy Product owned, visit by extension agents and size of the land owned as an important factor affecting Extent of commercialization measured as proportion of sales to total cash value of the Dairy
Product. The selection equation result depicts that about $81.82 \%$ of the variation in near of Dairy Product commercialization was explained by the independent variables used in the model.

Lack of marketing infrastructure, shortage in pastoral land and Dairy Product diseases were the major challenges hindering households from commercialization and Extent of commercialization of Dairy product. Among these reasons are food supply for household's consumption, generating income for supplementing the low income of basic livelihood sources, farming for the commercial purposes, and survival strategy in times of family and social crisis. One the major urban agriculture systems carried out in the city is the production of dairy.

The objective of this study was to identify the food security contributions of urban agriculture and the constraints and opportunities encountered with the sector in the city. The quantitative and qualitative methodologies are employed whereby structured questionnaires were prepared for the survey of randomly selected $\mathrm{HHs}$ among the smallholder city farmers. An in-depth case study on the selected HHs and observation of the study area were also the other statistical tools used by the researcher in the courses of the study. In addition to that, observations of the market places, interview with the retailers and whole sellers, and discussion with government officials were used for the researcher to have an insight about the realities of the study area. Thus, analysis of data was made based on the collected information through the stated research approaches that was fed into the computer software system for analysis, and interpretation and then came to concluding remark.

The study reveals, people that are engaged in urban agriculture are diverse in their background and social status also they start urban agriculture for various reasons primarily due to the low food availability at the household Extent, low income and unemployment. In an educational parameter the type of people engaged in urban agriculture varies from illiterate to a Extent of university graduate that signifies the need to engage in urban agriculture is not only for a single reason but using it either as the major source of livelihood, or an additional source of livelihood or as a survival strategy.

It was also found that urban agriculture contributes to those practitioners either as the direct source of food supply for the household members or improving their access for the purchase of food from the market. Thus, urban agriculture can be a source of income, can provide direct access to nutritionally rich foods (vegetable, fruit, and meat e.t.c) and a more varied diet, and can increase the stability of household food consumption against seasonality or other temporary shortages. 


\section{RECOMMENDATION}

Based on the findings of this study the following possible recommendations could be used as the cures for those constraints and shortcomings encountered in the courses of the study.

a. The continuous assessment of urban agriculture benefits for food security and consideration it with the national food production records could be the first-hand measure to be taken by those concerned bodies like policy makers.

b. The inclusion of urban agriculture interventions in the national food security programs should be the concern of the state. Also, Mekelle city administrator should be pay attention to the potential of urban agriculture specifically the Dairy production for improving households' food and livelihood security.

c. Improving urban agriculture requires a more direct, more focused, and more integrated approach. However, urban agriculture has been excluded and poorly defined in the formulation of policies and strategies of other relevant institutions. Thus, Urban Agriculture should be formulated into a policy framework to exploit the potential contribution of urban agriculture to food and livelihood security and environmental protection through the sustainable use and management of the existing resources.

d. It was understood that urban agriculture practitioners do not enjoy the same support from the governments as do their rural counterparts. The exclusion of urban agriculture created poor structural linkages of Urban Agriculture Extension Core Process with the ministry of agriculture which significantly reduced effectiveness and efficiency. Thus, emphasis should be given for the effective institutional set up of urban agriculture and extension. Also, a considerable attention should be given for the improvement of urban agriculture extension and allocation of resources specially deployment of agricultural expertise with the desired quantity and quality.

e. The issue of urban agriculture should be shifted from the scientific and research concern to the urban development and policy agenda.

f. Foundation should be laid down for the linkages and integrations of research and technologies with urban agriculture extension. Integrate the urban agriculture into the urban planning and management, allotting a certain area for urban agriculture, the master plan should encompass the zoning of urban agriculture and land use. Besides, effective coordination \& integration of all stakeholders (GOs, NGOs, \& Public Sector etc) involved in the production, processing and marketing of urban agriculture. g. In a bid to improve the wellbeing of people engaged in urban agriculture, efforts should be exerted to develop marketing facilities that would have the significant role to reduce the post-harvest loss of UA products and price manipulation by the middle men while UA products are brought to the market.

\section{ACKNOWLEDGEMENTS}

This research has been sponsored by College of Business and Economics, Mekelle University.

\section{REFERENCES}

Buechler, S., Hertog, W. Veenhuizen, R. van. (2002). Editorial. Urban Agriculture Magazine, no 8.Leusden, RUAF.

Buechler, S. and Devi, G.( 2006). Adaptations of wastewater-irrigated farming systems: a case study of Hyderabad, India. In van Veenhuizen, R. Cities farming for the future: urban agriculture for green and productive cities. RUAF Foundation/IDRC/IIRR, Leusden.

Burleigh, J.R. \& Black, L.L. (2001) . Supporting farmers towards safe year-round vegetables in periurban Manila. Urban Agriculture Magazine, no 3. January 2001. Health and urban agriculture. Leusden, RUAF.

FAO: (2007): profitability and sustainability of urban and peri-urban agriculture, agricultural management, marketing and finance, occasional paper

FAO. (1999). Urban and peri-urban agriculture: a new challenge for the UN Food and Agriculture Organization, by A.W. Drescher \& D. Iaquinta. Rome. (Internal report)

FAO. (2000). Food for the cities: food supply and distribution policies to reduce urban food insecurity, by O.Argenti. Rome.

FAO. (2001a). A briefing guide for the successful implementation of urban and peri-urban agriculture in developing countries and countries of transition. Revision 2, Handbook Series. Volume III.Rome.

FAO (2001b). Livestock keeping in urban areas, a review of traditional technologies, by J.B. Schiere, \& R. Van Der Hoek. R. Animal Production and Health Papers. 151. Rome.

Glenn D. Israel, (1992): determine sample size, university of Florida. 
Ibrahim Game And Richaela Primus,( 2015).urban agriculture: state university of new york college of forestry and environmental science

Nigatu Alemayehu, Dirk Hoekstra And Azage Tegegne, (2012). smallholder dairy value chain development: international livestock research institute

Roseline J Akinlade, Olubunmi L Balogun, Adekemi A Obisesan, (2013). commercialization of urban farming: the case of vegetable farmers in southwest Nigeria, invited paper presented at the 4th international conference of the African association of agricultural economists, September 22-25
Stephen R. Bond, (2002). Dynamic Panel Data Models: A Guide to Micro Data Methods and Practices. The Institute For Fiscal Studies Department Of Economics, UCL Cemmap

Working Paper CWP09/02 (2002). Ridgmount Street, London, WCIE 7AE, UK.

Wooldgridge, Jeffrey M., (2010). Econometric Analysis of Cross section and Panel Data.

Verbeek, Marno, (2004). A Guide to Modern Econometrics. 2nd ed. John Wiley \& Sons Ltd, theAtrium, Southern Gate, Chichester, West Sussex PO19 8SQ, England. 
This page is intentionally left blank 